\title{
Rectitis post-radioterapia diagnosticada con imagen de banda estrecha
}

\author{
J. Egea Valenzuela, F. Alberca de las Parras, F. Carballo Álvarez y J. Molina Martínez
}

Servicio de Aparato Digestivo. Sección de Endoscopia Digestiva. Hospital Universitario

Virgen de la Arrixaca. Murcia

El daño inducido por las radiaciones en el tubo digestivo es relativamente frecuente tras el tratamiento de diferentes neoplasias. Las localizaciones más habituales son recto y sigma y se estima que hasta un $10 \%$ de los pacientes que reciben radioterapia pélvica pueden presentar algún síntoma derivado. La afectación puede ser aguda, durante el propio tratamiento, o crónica, hasta varios meses tras la exposición. Se manifiesta con diarrea, rectorragia, tenesmo, incontinencia, fístulas o cuadros obstructivos por la isquemia crónica. En muchas ocasiones se trata de un proceso silente, siendo el diagnóstico incidental.

Anatomopatológicamente se produce una endarteritis obliterante de origen isquémico de los vasos de pequeño tamaño de la submucosa. Endoscópicamente la afectación consiste en lesiones difusas de características angiodisplásicas, con mucosa friable e incluso presencia de ulceraciones en diferente grado de evolución.

Aunque se han propuesto diferentes opciones terapéuticas, sistémicas o tópicas, el tratamiento preferido, en centros con experiencia en su uso, es la coagulación de las lesiones con argón. Es una técnica que permite tratar las lesiones de forma dirigida, segura en manos expertas, de demostrada eficacia y con escasos efectos adversos.

Narrow Band Imaging (NBI) es un sistema de visualización endoscópica basado en la modificación del ancho de banda de la luz emitida y que permite una valoración más detallada de la superficie mucosa, así como un estudio más preciso del patrón vascular.

Se presenta el caso de un paciente de 66 años, afecto de un adenocarcinoma de próstata, tratado con terapia hormonal y radioterapia. Aproximadamente un año después de finalizar este tratamiento, el paciente es incluido en el programa de cribado de cáncer colorrectal de nuestro servicio. Presenta test de sangre oculta en heces positivo y, por tanto, es sometido a una colonoscopia. Durante la misma apreciamos una importante rectitis actínica, con presencia de múltiples lesiones difu-

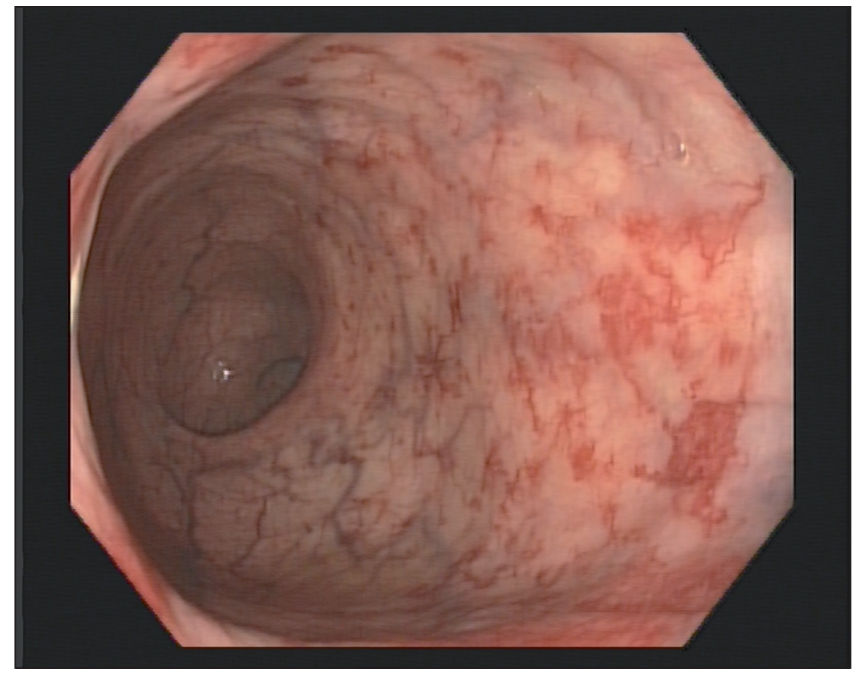

Fig. 1. Visión de las lesiones con endoscopia convencional.

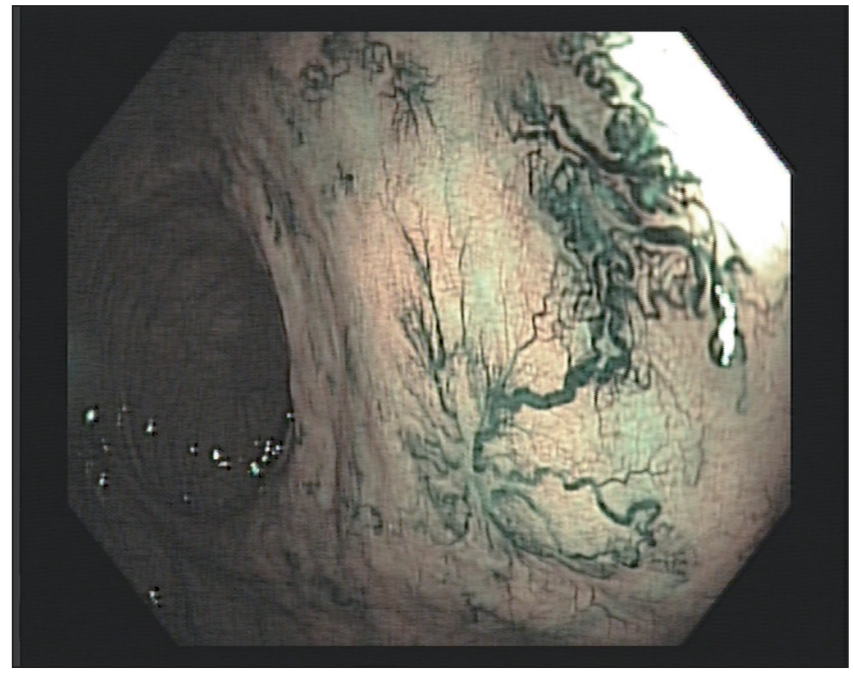

Fig. 2. Las mismas lesiones vistas con NBI. 
sas de aspecto teleangiectásico (Fig. 1). La exploración se realizó con un equipo de alta definición equipado con NBI, siendo las imágenes obtenidas con éste especialmente reveladoras de la naturaleza de las lesiones, además de espectáculares y poco habituales (Fig. 2). El paciente se trató en dos sesiones mediante fotocoagulación con argón (Fig. 3), sin presentar efectos adversos y con erradicación de todas las lesiones.

\section{BIBLIOGRAFÍA}

1. Babb RR. Radiation proctitis: a review. Am J Gastroenterol. 1996 Jul; 91(7): 1309-11.

2. Sebastian S, O’Connor H, O’Morain C, Buckley M. Argón plasma coagulation a first-line treatment for chronic radiation proctopathy. J Gastroenterol Hepatol. 2005; 20(2):171-2.

3. Wilson SA, Rex DK. Endoscopic treatment of chronic radiation proctopathy. Curr Opin Gastroenterol. 2006; 22: 536.

4. Postgate A, Saunders B, Tjandra J, Vargo J. Argon plasma coagulation in chronic radiation proctitis. Endoscopy. 2007; 39: 361-5.

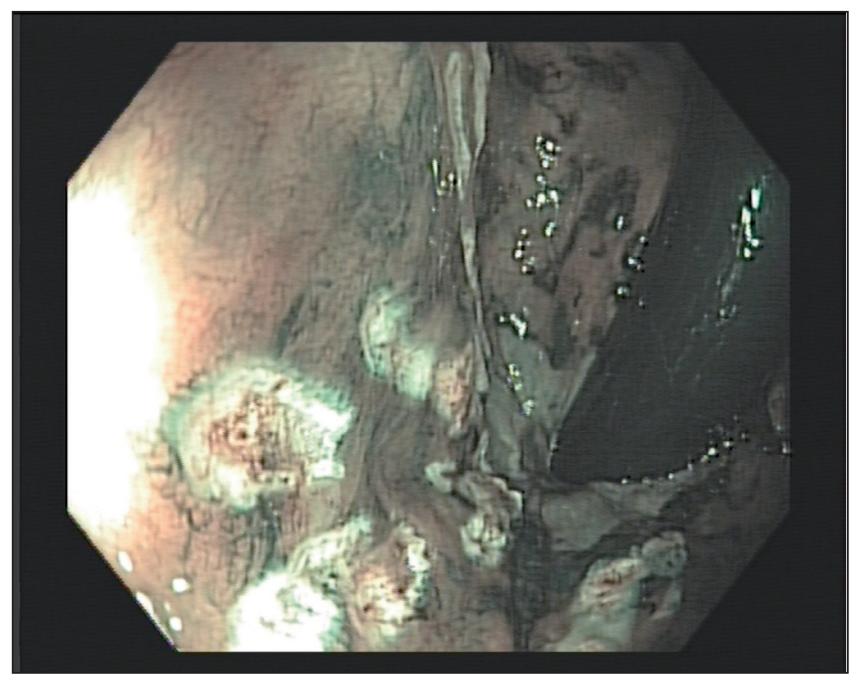

Fig. 3. Las lesiones vistas en retroflexión tras la primera sesión de tratamiento con argón. 